\title{
Benefits from Treatment and Control of Patients with Resistant Hypertension
}

\author{
Michael Doumas, ${ }^{1}$ Vasilios Papademetriou, ${ }^{2}$ Stella Douma, ${ }^{3}$ Charles Faselis, ${ }^{1}$ \\ Konstantinos Tsioufis, ${ }^{2}$ Eugene Gkaliagkousi, ${ }^{3}$ Konstantinos Petidis, ${ }^{3}$ \\ and Chrysanthos Zamboulis ${ }^{3}$
}

\author{
${ }^{1}$ Veterans Affairs Medical Center, George Washington University, Washington, DC 20422, USA \\ ${ }^{2}$ Veterans Affairs Medical Center, Georgetown University, Washington, DC 20422, USA \\ ${ }^{3}$ 2nd Propaedeutic Department of Internal Medicine, Aristotle University of Thessaloniki, \\ 49 Konstantinoupoleos Street, 54643 Thessaloniki, Greece
}

Correspondence should be addressed to Michael Doumas, michalisdoumas@yahoo.co.uk

Received 11 October 2010; Accepted 16 November 2010

Academic Editor: A. Gradman

Copyright ( $) 2011$ Michael Doumas et al. This is an open access article distributed under the Creative Commons Attribution License, which permits unrestricted use, distribution, and reproduction in any medium, provided the original work is properly cited.

\begin{abstract}
Resistant hypertension is commonly found in everyday clinical practice. However, the risks of resistant hypertension, as well as the benefits of treatment and control of blood pressure in patients with resistant hypertension remain vaguely clarified. Data from small clinical studies and observational cohorts suggest that patients with resistant hypertension are at increased cardiovascular risk, while control of blood pressure offers substantial benefits. It has to be noted however that data from appropriate large randomized studies are missing, and resistant hypertension remains remarkably understudied. Resistant hypertension has attracted significant scientific interest lately, as new therapeutic modalities become available. The interventional management of resistant hypertension either by carotid baroreceptor stimulation or renal sympathetic denervation is currently under investigation with promising preliminary results. This review presents available evidence regarding the benefits of treatment and control of blood pressure in patients with resistant hypertension and offers a critical evaluation of existing data in this field.
\end{abstract}

\section{Introduction}

Resistant hypertension is defined as uncontrolled blood pressure despite the use of optimal doses of three antihypertensive medications, of which one is a diuretic [1]. Although this definition encompasses a large number of patients, many of these patients can be controlled with more careful adjustment of their regimen and implementation of good practices. Several factors have been identified as contributors to resistant hypertension: poor patient adherence, physician inertia, inadequate doses or inappropriate combinations of antihypertensive drugs, secondary forms of hypertension, drug-induced hypertension, excess alcohol intake, and volume overload [2]. Lifestyle modifications including salt restriction are very important in these patients [3]. Addressing some of the comorbid conditions, such as sleep apnea, primary aldosteronism [4], or addition of adjunct therapies such as spironolactone [5-11] can achieve blood pressure control. However, many patients remain uncontrolled despite the use of four, five, or six antihypertensive drugs, especially in everyday clinical practice, outside the "sterile" environment of clinical trials. It is surprising to realize that although hypertension is among the most studied diseases, resistant hypertension which denotes the most severe, high-risk, and probably more scientifically interesting subgroup remains so much understudied.

Unfortunately, data regarding the natural history of resistant hypertension is limited. Furthermore, the benefits of controlling blood pressure in patients with resistant hypertension are vaguely clarified, and it seems that they will continue to remain as such, since it is unethical to perform a randomized study with a control group of resistant hypertensives that will remain untreated. Since direct data is not available, only clinically meaningful assumptions can 
be made based on indirect information and using common sense. Therefore, for the purpose of this paper we'll use data from the past (before the era of antihypertensive therapy), data from clinical studies involving patients with severe or malignant hypertension, data from small clinical studies in patients with resistant hypertension, and from subgroups of patients included in large clinical trials.

This paper attempts to present available evidence regarding the benefits of treatment and control of resistant hypertension, to highlight the significant scarcity of data in this population, and to critically evaluate the use of data from other hypertensive subgroups for extrapolation in resistant hypertension.

\section{Data on Malignant Hypertension: Lessons from the Past}

The risks of resistant hypertension and the benefits of its management remind one of the story of malignant hypertension. Although uncontrolled or resistant hypertension is a different entity from malignant hypertension, it is well known that in the long term, untreated or uncontrolled hypertension can lead to "accelerated/malignant" phase (VA studies). The term malignant hypertension was introduced by Volhard and Fahr in 1914 for patients with severe hypertension and renal insufficiency [12]. The term was abandoned until the landmark studies performed at Mayo Clinic by Keith and Wagener. It was observed that the prognosis of malignant hypertension was extremely grave. In the first study from Mayo Clinic, only 7 out of 81 patients with malignant hypertension were still alive after the fifty months of followup, while the average length of life was eight months [13]. Retinitis was highlighted as an essential part of malignant hypertension and was significantly associated with mortality; the average length of life in patients with Grade I retinitis was 17 months and that of patients with Grade IV retinitis was 2 months. In a later study of 146 patients, only 1 patient was alive at the end of five-year follow-up period [14]. Further reports of more than 1400 patients with malignant hypertension have confirmed the findings of Mayo Clinic and revealed that the five-year mortality was over $90 \%$, even until the 60s [15-18]. It's worth noting that no therapy was available at that time. Protein and salt restriction, the rice diet, and mild sedatives were used for the treatment of hypertension; however, the results were all but hopeless regarding long-term improvements [1923]. Therefore, other therapeutic approaches for malignant hypertension were considered.

Experimental and human studies have revealed the central role of SNS in the pathogenesis of arterial hypertension. Due to the lack of effective therapeutic measures for malignant hypertension, sympathectomy was proposed by many physiologists, such as Pende, Danielopolu, and Jonnesco. Sympathectomy was tested up, that point, for the management of peripheral vascular disease (Jaboulay and Leriche in France), angina pectoris (Jonnesco and Danielopolu in Romania), spastic paralysis (Royle and Hunter in Australia), and Raynaud's disease and scleroderma

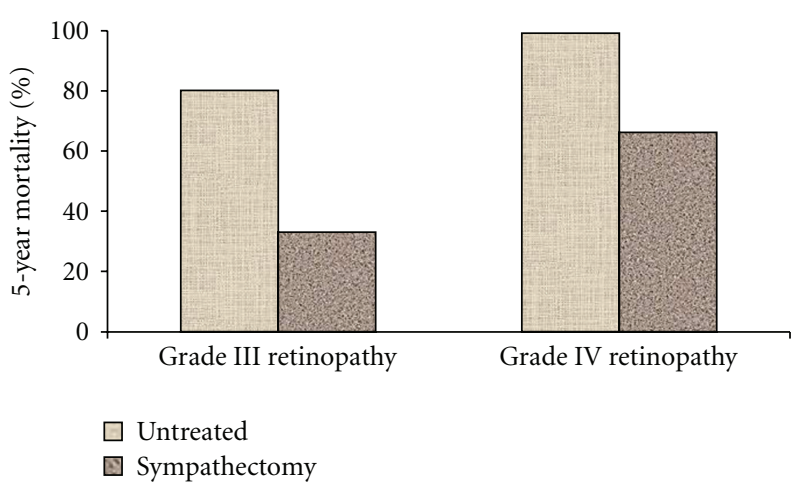

FIGURE 1: Five-year mortality rates (\%) in untreated patients with malignant hypertension and Grade III or IV retinopathy compared to similar patients that underwent sympathectomy (modified from Keith et al. [25] and Peet et al. [26]).

in Germany (Bruening). Sympathectomy for the treatment of malignant hypertension appears to have taken place for the first time in Germany as early as 1923 [24]. It was introduced in the US by Alfred Adson at the Mayo Clinic and by Max Peet at Ann Arbor. It was rapidly realized that sympathectomy dramatically increased the survival of patients with malignant hypertension. The five-year mortality rates of patients with Grade IV retinopathy fell from $99 \%$ at the Keith Wagener series to $66.5 \%$ in sympathectomized patients $[25,26]$; similar impressive improvements were observed in patients with Grade III retinopathy (Figure 1).

The pioneer work of Peet, Adson Crile, Hener, Page, Grimson, Hinton, and others was reinforced by Reginald Smithwick, who established the operation worldwide as an effective method of lowering blood pressure in patients with malignant hypertension. Until 1960, a plethora of papers reported the effects of sympathectomy in several thousand patients with malignant hypertension all over the world [2738], pointing towards dramatic improvements in the survival of operated patients [39] when compared to conservative management (Figure 2).

The indications for sympathectomy waxed and waned during this period. The operation was initially reserved for patients with severe hypertension without significant target organ damage (heart failure, chronic renal disease, angina), was later performed irrespective of the organ damage, and finally restricted to patients without chronic complications since the benefits were more apparent in such patients. Similarly, the extent of the operation varied between the different centers, due to the incomplete understanding of sympathetic anatomy and the absence of appropriate studies comparing the various surgical approaches. The common denominator of all operating techniques was the need for prolonged hospitalization and long recovery period. Another annoying aspect of sympathectomy was the lack of satisfactory predictors of blood pressure response to the operation. Although several tests have been used, the results were inconclusive and sometimes misleading.

The most important limitation of sympathectomy was the safety of the procedure. Adverse events were frequent 


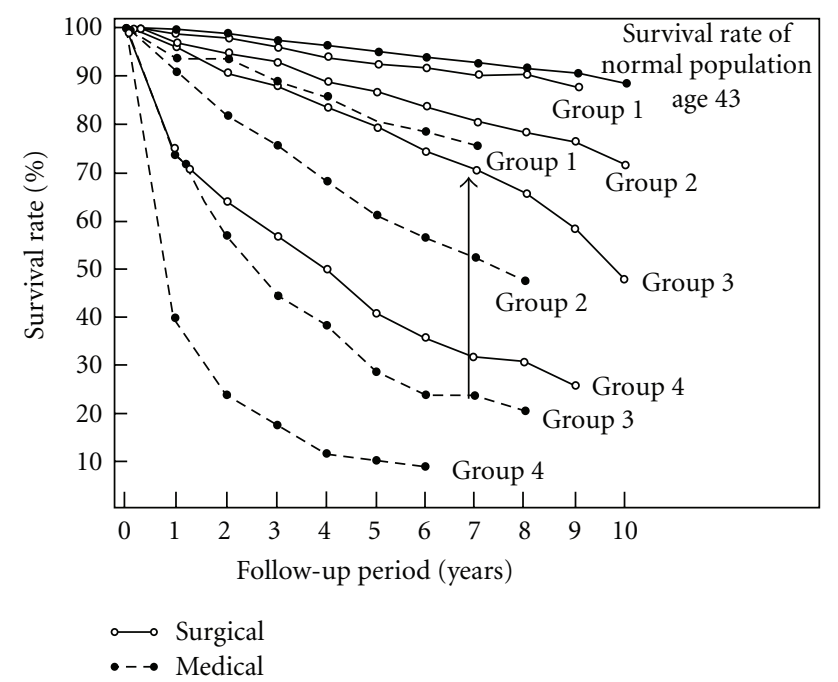

FIGURE 2: Survival rates in patients with malignant hypertension at various stages (Group 1-4) treated either medically or surgically (modified from Smithwick and Thompson [39]).

and annoying, such as orthostatic hypotension, perioperative pain, orthostatic tachycardia, anhidrosis, intestinal and sexual problems, and palpitations, while more serious complications have been reported, such a perioperative death, stroke, myocardial infarction, paraplegia, and spinal cord injury. The operation was unpleasant and intolerant and many hypertension experts remained skeptical; Ed Weiss stated in 1937 "... and now to cap the climax of his difficulties the unfortunate person with hypertension seems about to fall into the clutches of the neurosurgeon who is prepared to separate him from his sympathetic nervous system", while Homer Smith used the words "investigation and desperation" for sympathectomy. It was not until the introduction of effective antihypertensive drug therapy that the benefits and risks of sympathectomy were fully reevaluated.

The interest in sympathectomy faded quite suddenly with the advent of antihypertensive therapy. Centrally acting drugs (ganglion-blocking agents, reserpine) have offered similar beneficial effects [40] (Figure 3). The introduction of diuretics has closed the circle of sympathectomy in the treatment of hypertension, highlighting that therapeutic options fade away when new, more promising treatments appear. Of note, blood pressure control significantly affected the survival of treated patients [40] (Figure 4), underlining that uncontrolled hypertension is associated with increased mortality rates.

\section{Data from Trials in Severe Hypertension: The VA Study}

Despite the impressive benefits of antihypertensive drugs that have established their use in the treatment of malignant hypertension, their role in the treatment of milder forms of hypertension remained controversial for a significant period of time. Even in 1966, it was stated in the book Controversy

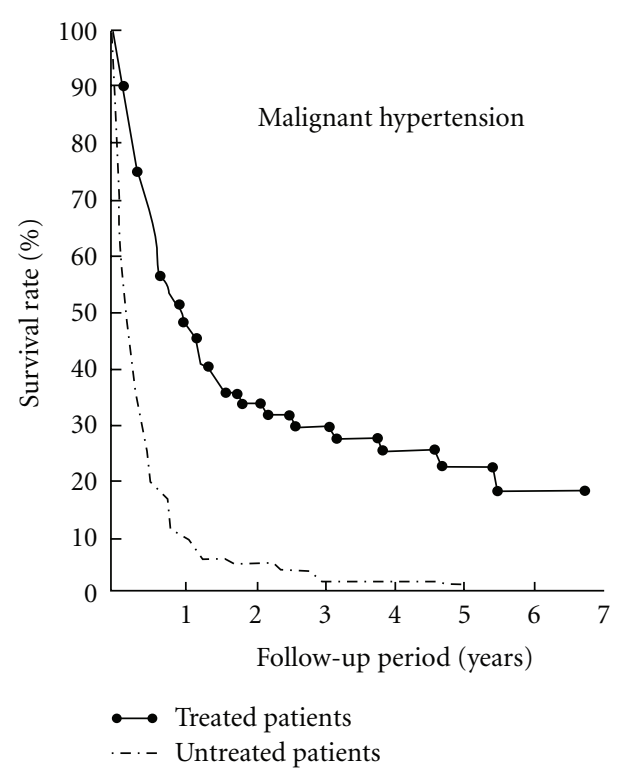

FIGURE 3: Survival rates in untreated and medically treated patients with malignant hypertension (modified from Harington et al. [40]).

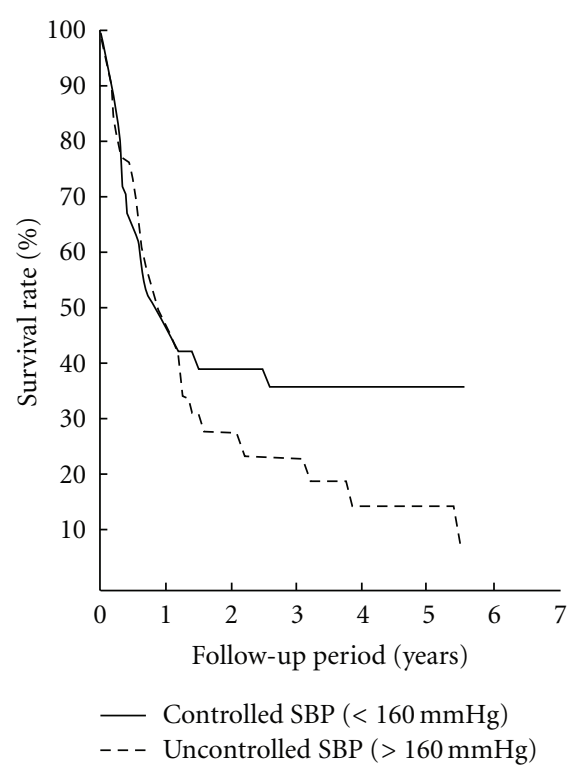

FIGURE 4: Survival rates in medically treated patients with malignant hypertension according to blood pressure control (modified from Harington et al. [40]).

in Internal Medicine that drug treatment of essential hypertension was not beneficial [41]. Several reasons contributed to the "resistance" of hypertension specialists, primary care physicians, and relevant authorities to recognize the benefits of antihypertensive therapy. Those benefits include the following.

(a) The general belief that vascular changes represent a primary pathologic process that is independent of blood pressure levels. Hypertension was considered to be merely a symptom and not the cause of vascular 
complications, therefore the motto "treat the patient, not the manometer" was adopted by the majority.

(b) The inheritance of Sir William Osler promoted therapeutic nihilism. The nihilistic attitude regarding the role of drug therapy may be attributed to Osler's quote: "one of the first duties of the physician is to educate the masses not to take medicine" [42]. However, this was probably a misinterpretation of Osler's beliefs, since Osler was referring to the drugs available at his time, the use of which reached the limits of charlatanism, and not modern antihypertensive drugs that were not available at his time.

(c) The special emphasis and the exaggerated focus that were given in secondary forms of hypertension, the prevalence of which was largely overestimated and absorbed the vast majority of available grants. The opinion that one has to find the cause before treating the disease has prevailed, thus rendering "empiric" antihypertensive therapy "a shot in the dark", an approach that was not appreciated at all. However, the cause of hypertension remained unknown for the vast majority of patients, and it was not unusual for such patients to remain untreated.

(d) The role of preventive medicine was not considered crucial and had not gained wide popularity at that time. Patients, physicians, and the media were not stuck by the benefits of prevention, since the whole society was not ready to move from therapy to prevention.

(e) Maybe the most important factor that restricted the wide adoption of antihypertensive drugs was the lack of convincing clinical studies to verify the benefits of treating essential hypertension.

The first organized data demonstrating benefit from the treatment of severe hypertension came from the Veterans Administration study group. Under the leadership of Edward Freis the first placebo controlled study was carried out in patients with severe hypertension. In that study (published in 1967), 143 patients with severe untreated hypertension (diastolic $>115 \mathrm{mmHg}$ ) were randomized to either treatment or placebo [43]. In only 20 months, it became apparent that treatment of these patients with severe blood pressure elevation was dramatically beneficial. Twenty-six events occurred in the placebo arm and only 1 in the treated arm (Table 1). It is important to note that 12 out of 26 events were accelerated hypertension leading to malignant hypertension. Since then, the standard of care is to treat severe hypertension; it is unlikely that the study will be repeated. Although the study was placebo controlled, it is reasonable to assume that even treated patients who remain with severe blood pressure elevations (i.e., resistant to treatment) will have similarly bad prognosis.

Confirmation of this assumption comes from many longitudinal studies, cohorts, or subgroup analyses. In the Australian National Blood Pressure study, early in the antihypertensive therapy era, it was shown that patients with uncontrolled blood pressure despite triple therapy had a
TABLE 1: Fatal and nonfatal events at the VA trial in patients with severe hypertension receiving active treatment (HCTZ, reserpine, and hydralazine) or placebo (modified from the VA collaborators [43]).

\begin{tabular}{lcc}
\hline Events & $\begin{array}{c}\text { Active treatment } \\
n=73\end{array}$ & $\begin{array}{c}\text { Placebo } \\
n=70\end{array}$ \\
\hline Deaths & 0 & 4 \\
Stroke & 1 & 4 \\
Coronary events & 0 & 2 \\
Heart failure & 0 & 2 \\
Renal damage & 0 & 2 \\
Accelerated hypertension & 0 & 12 \\
\hline
\end{tabular}

four-fold increased risk for cardiovascular events compared to patients with controlled blood pressure [44-46].

\section{Data from Small Clinical Studies}

Virtually no longitudinal study has addressed the particular prognosis of resistant hypertension. Relevant information may be extracted only from small clinical studies. Isakson and Ostergren studied 36 patients with resistant hypertension in Sweden for a 7-year follow-up period [47]. For each of these patients, two control patients were randomly selected from a reference group (retrospectively, matched for age and gender), and the outcomes of the two groups were compared. It has been shown that patients with resistant hypertension had an almost 3-fold increased risk for cardiovascular events (stroke, transient ischemic attacks, myocardial infarction, death, heart failure, renal failure, new onset diabetes) compared to patients with controlled hypertension (odds ratio $2.71 ; P<.05$ ).

Redon conducted, in Spain, a prospective study of 86 patients with resistant hypertension (diastolic blood pressure $>100 \mathrm{mmHg}$ ) and a long follow-up period (49 months average) using ambulatory blood pressure measurement (ABPM) [48]. It was reported that patients with poorly controlled blood pressure (daytime diastolic blood pressure $>97 \mathrm{mmHg}$ ) had more than 6 times higher relative risk for morbid cardiovascular events (relative risk: 6.42; 95\% CI: 1.39-29.7; $P=.017$ ) compared to patients with relatively controlled blood pressure (daytime diastolic blood pressure $<88 \mathrm{mmHg}$ ) (Figure 5). It should be noted, however, that the number of patients and events were relatively small, office blood pressure was not independently associated with morbid events, data regarding systolic blood pressure were not provided, and the cut-off limit of daytime diastolic blood pressure $(88 \mathrm{mmHg}$ ) was higher than what is currently considered normal ( $85 \mathrm{mmHg}$ ).

Pierdomenico in Italy studied a larger number of patients (130 resistant hypertensives) for a slightly longer follow-up period (4.98 \pm 2.9 years) using ABPM as well [49]. Moreover, the study compared the outcomes of patients with true resistant hypertension (high clinic and ambulatory blood pressure) to the outcomes of patients with false resistant hypertension (high clinic and normal ambulatory blood 


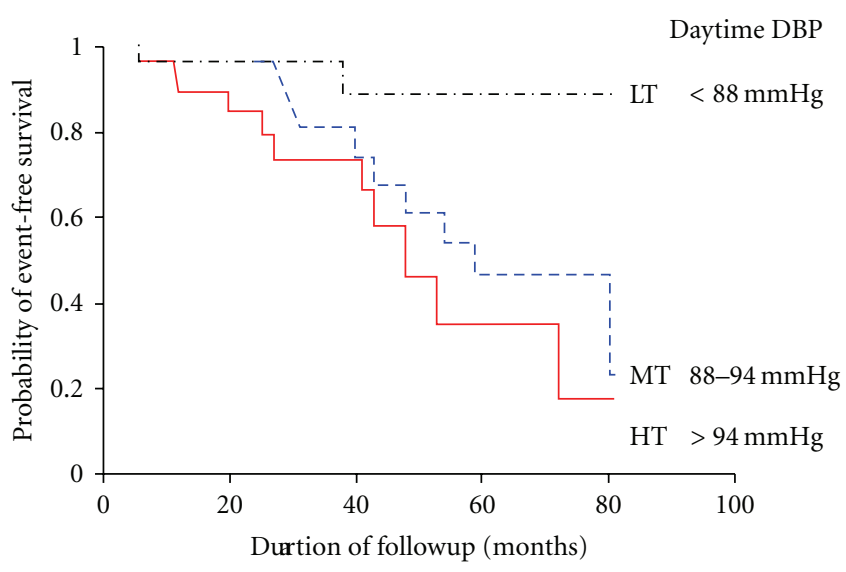

Figure 5: Probability of event-free survival in patients with resistant hypertension according to daytime diastolic blood pressure (modified from Redon et al. [48]).

pressure) and controlled hypertension (normal clinic and ambulatory blood pressure). It was shown that patients with true resistant hypertension had an almost 3-fold increased relative risk for cardiovascular events (relative risk: 2.94; 95\% CI: $1.02-8.41 ; P<.05)$ compared to patients with controlled blood pressure.

More recently, Salles in Brazil studied an even larger number of patients with resistant hypertension (556 patients) for a median follow-up period of 4.8 years [50]. It was reported that resistant hypertension was an independent predictor for cardiovascular and all-cause mortality. Moreover, it was shown that patients with resistant hypertension had increased cardiovascular and all-cause mortality compared to patients with false resistant hypertension (hazard ratio: 2.30; 95\% CI: 1.42-3.74). Recent studies from the same group have shown the prognostic value of nocturnal blood pressure, the ambulatory arterial stiffness index, the electrocardiographic strain, and the ventricular repolarization in patients with resistant hypertension [51-54]. The above findings along with the superiority of ambulatory over office blood pressure measurements in patients with resistant hypertension underline the importance of taking into account other factors, beyond office blood pressure, in the management of patients with resistant hypertension.

Magnanini studied 382 Brazilian women with resistant hypertension and found that cardiovascular events (death, ischemic heart disease, stroke, nephropathy) were higher in patients with uncontrolled hypertension, as compared to those with controlled blood pressure (5.8 versus 3.7 per 100 women/years, resp.), although the difference did not reach statistical significance $(P=.06)$ [55]. However, daytime blood pressure was found to be an independent risk predictor (relative risk: 1.67; 95\% CI: $1.00-2.78 ; P<.05$ ).

\section{Data from Large Clinical Trials}

The lack of reliable data regarding the outcome of uncontrolled versus controlled blood pressure in patients with resistant hypertension using hard endpoints justifies other approaches. One can use data from other patient populations and make rational assumptions, although extrapolation carries inherent risks and has severe limitations.

For example, in a large cohort of hypertensive males $(4,714$ patients), it has been shown that cardiovascular mortality was almost twice as high in male patients with uncontrolled hypertension compared to patients with wellcontrolled blood pressure (risk ratio: 1.66; 95\% CI: 1.042.64 ), although particular data regarding resistant hypertension are not provided [56]. In another cohort of 11,912 veteran male patients followed for 15 years, uncontrolled hypertension (systolic blood pressure $>150 \mathrm{mmHg}$ ) was associated with increased risk of end-stage renal disease (risk ratio: 3.00 ; 95\% CI: 2.09-4.55; $P<.001$ ) [57]. Is this exaggerated cardiovascular risk of uncontrolled hypertension applicable in resistant hypertension? Common sense dictates that there is no reason to assume the opposite. Until convincing data becomes available, it seems clinically wise to assume that controlling blood pressure in resistant hypertension is beneficial, and treating physicians should make every possible effort towards this direction.

Relevant information can be obtained from large clinical trials. Although no trial has been specifically designed to evaluate the benefits of blood pressure control in resistant hypertension, data from recent large trials regarding patients that fulfill the definition of resistant hypertension will be valuable until the conduction of a study devoted to resistant hypertension. We have to keep in mind, however, the inherent limitations of such studies, that besides the post-hoc analysis, they have used unusual antihypertensive regimes, which are seldom used in everyday clinical practice.

In the ASCOT trial, the combination of older drugs (diuretics + beta blockers) was compared to newer drugs (ACEinhibitors + calcium antagonists) [58]. In patients not achieving blood pressure control, alpha blockers have been added as third-line and spironolactone as fourth-line therapy. It is obvious that some patients from the diuretic/beta blocker group may be labeled as resistant hypertensives when the addition of alpha blockers was ineffective. It should be, recognized however, that the combination of a diuretic with a beta- and an alpha-blocker is uncommon in everyday clinical practice. Calcium antagonists or agents acting on the reninangiotensin axis or a combination of both are used for the vast majority of uncontrolled patients.

Similar problems are applicable to the ACCOMPLISH trial, which compared the combination of an ACEinhibitor with diuretics or calcium antagonists [59]. Uncontrolled patients were allowed to use beta blockers. Therefore patients from the first group that remained uncontrolled with the triple combination of ACEinhibitors, diuretics, and betablockers can be characterized as resistant hypertensives and be used as a source of valuable data extraction. This combination is more clinically meaningful than the one used in the ASCOT trial, even this, however, excludes the use of calcium antagonists, which are among the most commonly prescribed drugs in the western world for the treatment of resistant hypertension.

The ALLHAT trial confronts similar problems. Patients were assigned to receive diuretics, ACEinhibitors, calcium 
antagonists, or alpha-blockers, and were allowed to use betablockers, clonidine, or hydralazine in case the blood pressure remained above goal [60]. Patients included in the diuretic group that remained uncontrolled despite the use of two additional drugs meet the criteria of resistant hypertension. However, as one can easily notice, the drug combinations that were actually used in this study are seldom used in everyday clinical practice.

\section{Conclusions}

Data from large clinical trials in different subgroups of hypertensive patients suggest an increased prevalence of resistant hypertension. Data regarding the risks of resistant hypertension, as well as the benefits of treatment and control of blood pressure in resistant hypertensive patients is scarce. However, data from small clinical studies and observational cohorts consistently points towards an increased cardiovascular risk in patients with resistant hypertension. Moreover, available information suggests that there is substantial benefit from appropriate treatment and control of resistant patients. Recent randomized studies in resistant hypertension assessed the efficacy and safety of either new drugs (such as darusentan) $[61,62]$ or interventional techniques (such as carotid baroreceptor stimulation or renal sympathetic denervation) $[63,64]$. We believe that appropriate large, long-term studies are needed to evaluate the prevalence and the risks of resistant hypertension, as well as the significant benefits of treating and controlling resistant hypertension.

\section{References}

[1] D. A. Calhoun, D. Jones, S. Textor et al., "Resistant hypertension: diagnosis, evaluation and treatment," Hypertension, vol. 117, pp. 510-526, 2008.

[2] P. A. Sarafidis and G. L. Bakris, "Resistant hypertension: an overview of evaluation and treatment," Journal of the American College of Cardiology, vol. 52, no. 22, pp. 1749-1757, 2008.

[3] E. Pimenta, K. K. Gaddam, S. Oparil et al., "Effects of dietary sodium reduction on blood pressure in subjects with resistant hypertension: results from a randomized trial," Hypertension, vol. 54 , no. 3, pp. 475-481, 2009.

[4] S. Douma, K. Petidis, M. Doumas et al., "Prevalence of primary hyperaldosteronism in resistant hypertension: a retrospective observational study," The Lancet, vol. 371, no. 9628, pp. 1921-1926, 2008.

[5] M. K. Nishizaka, M. A. Zaman, and D. A. Calhoun, "Efficacy of low-dose spironolactone in subjects with resistant hypertension," American Journal of Hypertension, vol. 16, no. $11 \mathrm{I}$, pp. 925-930, 2003.

[6] A. Mahmud, M. Mahgoub, M. Hall, and J. Feely, "Does aldosterone-to-renin ratio predict the antihypertensive effect of the aldosterone antagonist spironolactone?" American Journal of Hypertension, vol. 18, no. 12, pp. 1631-1635, 2005.

[7] Y. Sharabi, E. Adler, A. Shamis, N. Nussinovitch, A. Markovitz, and E. Grossman, "Efficacy of add-on aldosterone receptor blocker in uncontrolled hypertension," American Journal of Hypertension, vol. 19, no. 7, pp. 750-755, 2006.

[8] F. De Souza, E. Muxfeldt, R. Fiszman, and G. Salles, "Efficacy of spironolactone therapy in patients with true resistant hypertension," Hypertension, vol. 55, no. 1, pp. 147-152, 2010.
[9] D. A. Lane, S. Shah, and D. G. Beevers, "Low-dose spironolactone in the management of resistant hypertension: a surveillance study," Journal of Hypertension, vol. 25, no. 4, pp. 891-894, 2007.

[10] N. Chapman, J. Dobson, S. Wilson et al., "Effect of spironolactone on blood pressure in subjects with resistant hypertension," Hypertension, vol. 49, no. 4, pp. 839-845, 2007.

[11] H. K. Parthasarathy, K. Alhashmi, A. D. McMahon et al., "Does the ratio of serum aldosterone to plasma renin activity predict the efficacy of diuretics in hypertension? Results of RENALDO," Journal of Hypertension, vol. 28, no. 1, pp. 170$177,2010$.

[12] F. Volhard and T. Fahr, Die Brightsche Nierenkrankheit, Klinik, Pathologie und Atlas, Springer, Berlin, Germany, 1914.

[13] H. P. Wagener, "The retinitis of malignant hypertension," Transactions of the American Ophthalmological Society, vol. 25, pp. 349-380, 1927.

[14] N. M. Keith, H. P. Wagener, and J. W. Kernohan, "The syndrome of malignant hypertension," Archives of Internal Medicine, vol. 41, pp. 141-157, 1928.

[15] B. Hood, "Five and a half years experience of combination of antihypertensive drugs: main present difficulties," in Hypotensive Drugs, M. Harington, Ed., pp. 135-148, Pergamon Press, New York, NY, USA, 1956.

[16] P. Kincaid-Smith, J. McMichael, and E. A. Murphy, "The clinical course and pathology of hypertension with papilloedema (malignant hypertension)," The Quarterly Journal of Medicine, vol. 27, no. 105, pp. 117-153, 1958.

[17] M. F. Schottstaedt and M. Sokolow, "The natural history and course of hypertension with papilledema (Malignant Hypertension)," American Heart Journal, vol. 45, no. 3, pp. 331-362, 1953.

[18] H. M. Perry Jr. and H. A. Schroeder, "The effect of treatment on mortality rates in severe hypertension; a comparison of medical and surgical regimens," A.M.A. Archives of Internal Medicine, vol. 102, no. 3, pp. 418-425, 1958.

[19] H. O. Mosenthal, "Clinical aspects of hypertension including malignant hypertension," Bulletin of the New York Academy of Medicine, vol. 14, pp. 349-360, 1938.

[20] C. P. Howard, "The diagnosis and treatment of malignant hypertension," Canadian Medical Association Journal, vol. 32, pp. 621-624, 1935.

[21] F. O. Simpson and F. H. Smirk, "The treatment of malignant hypertension," The American Journal of Cardiology, vol. 9, no. 6, pp. 868-873, 1962.

[22] W. Grobin, "Malignant hypertension and its treatment," Canadian Medical Association Journal, vol. 82, pp. 600-601, 1960.

[23] C. J. Bulpitt, "Prognosis of treated hypertension 1951-1981," British Journal of Clinical Pharmacology, vol. 13, no. 1, pp. 7379, 1982.

[24] B. Greenwood, "The origins of sympathectomy," Medical History, vol. 11, no. 2, pp. 165-169, 1967.

[25] N. M. Keith, H. P. Wagener, and N. W. Barker, "Some different types of essential hypertension: their course and prognosis," American Journal of the Medical Sciences, vol. 268, no. 6, pp. 336-345, 1974.

[26] M. M. Peet, W. W. Woods, and B. Braden, "The surgical treatment of hypertension," The Journal of the American Medical Association, vol. 115, pp. 1875-1885, 1940.

[27] I. H. Page and G. J. Heuer, "A surgical treatment of essential hypertension," The Journal of Clinical Investigation, vol. 14, pp. 22-26, 1935. 
[28] R. H. Smithwick, "Surgical treatment of hypertension," The American Journal of Medicine, vol. 4, no. 5, pp. 744-759, 1948.

[29] E. M. Isberg and M. M. Peet, "The influence of supradiaphragmatic splanchnicectomy on the heart in hypertension," American Heart Journal, vol. 35, no. 4, pp. 567-583, 1948.

[30] E. V. Allen, "Sympathectomy for essential hypertension," Circulation, vol. 6, no. 1, pp. 131-140, 1952.

[31] G. P. Whitelaw, D. Kinsey, and R. H. Smithwick, "Factors influencing the choice of treatment in essential hypertension. Surgical, medical or a combination of both," The American Journal of Surgery, vol. 107, no. 1, pp. 220-231, 1964.

[32] S. Hammarström and P. Bechgaard, "Prognosis in arterial hypertension. Comparison between 251 patients after sympathectomy and a selected series of 435 non-operated patients," The American Journal of Medicine, vol. 8, no. 1, pp. 53-56, 1950.

[33] J. A. Evans, "The place of splanchnicectomy in the treatment of hypertension," Canadian Medical Association journal, vol. 64, no. 1, pp. 47-50, 1951.

[34] J. W. Hinton, "End results of thoracolumbar sympathectomy for advanced essential hypertension," California Medicine, vol. 70, no. 4, pp. 282-287, 1949.

[35] K. S. Grimson, E. S. Orgain, and B. Anderson, "Results of treatment of patients with hypertension by total thoracic and partial to total lumbar sympathectomy, splanchnicectomy and celiac ganglionectomy," Annals of Surgery, vol. 129, pp. 850871,1949 .

[36] J. C. Harland and F. d'Abreu, "Lumbodorsal sympathectomy in severe hypertension," British Medical Journal, vol. 1, pp. 1019-1024, 1949.

[37] S. M. Chris, "Sympathectomy for hypertension," British medical journal, vol. 1, no. 4708, pp. 665-670, 1951.

[38] M. Doumas, C. Faselis, and V. Papademetriou, "Renal sympathetic denervation and systemic hypertension," American Journal of Cardiology, vol. 105, no. 4, pp. 570-576, 2010.

[39] R. H. Smithwick and J. E. Thompson, "Splanchnicectomy for essential hypertension; results in 1,266 cases," Journal of the American Medical Association, vol. 152, no. 16, pp. 1501-1504, 1953.

[40] M. Harington, P. Kincaid-Smith, and J. McMichael, "Results of treatment in malignant hypertension: a seven-year experience in 94 cases," British Medical Journal, vol. 2, no. 5158, pp. 969980, 1959.

[41] W. Goldring and H. Chasis, "Antihypertensive drug therapy," in Controversy in Internal Medicine, F. J. Ingelfinger, A. S. Relman, and M. Finland, Eds., pp. 83-91, WB Saunders, Philadelfia, Pa, USA, 1966.

[42] W. Osler, "Am address on high blood pressure: its associations, advantages, and disadvantages," British Medical Journal, vol. 2, pp. 1173-1177, 1912.

[43] Veterans Administration Cooperative Study Group on Antihypertensive Agents, "Effects of treatment on morbidity and mortality in hypertension: results in patients with diastolic blood pressures averaging 115-129 mmHg," The Journal of the American Medical Association, vol. 202, pp. 116-122, 1967.

[44] R. Reader, G. E. Bauer, and A. E. Doyle, "The Australian therapeutic trial in mild hypertension. Report by the Management Committee," The Lancet, vol. 1, no. 8181, pp. 1261-1267, 1980.

[45] P. I. Korner, G. E. Bauer, and A. E. Doyle, "Untreated mild hypertension. A report by the management committee of the Australian therapeutic trial in mild hypertension," The Lancet, vol. 1, no. 8265, pp. 185-191, 1982.
[46] The Management Committee of the Australian National Blood Pressure Study, "Prognostic factors in the treatment of mild hypertension,” Circulation, vol. 69, pp. 668-676, 1984.

[47] H. Isaksson and J. Ostergren, "Prognosis in therapy-resistant hypertension," Journal of Internal Medicine, vol. 236, no. 6, pp. 643-649, 1994.

[48] J. Redon, C. Campos, M. L. Narciso, J. L. Rodicio, J. M. Pascual, and L. M. Ruilope, "Prognostic value of ambulatory blood pressure monitoring in refractory hypertension: a prospective study," Hypertension, vol. 31, no. 2, pp. 712-718, 1998.

[49] S. D. Pierdomenico, D. Lapenna, A. Bucci et al., "Cardiovascular outcome in treated hypertensive patients with responder, masked, false resistant, and true resistant hypertension," American Journal of Hypertension, vol. 18, no. 11, pp. 14221428, 2005.

[50] G. F. Salles, C. R. L. Cardoso, and E. S. Muxfeldt, "Prognostic influence of office and ambulatory blood pressures in resistant hypertension," Archives of Internal Medicine, vol. 168, no. 21, pp. 2340-2346, 2008.

[51] E. S. Muxfeldt, C. R. L. Cardoso, and G. F. Salles, "Prognostic value of nocturnal blood pressure reduction in resistant hypertension," Archives of Internal Medicine, vol. 169, no. 9, pp. 874-880, 2009.

[52] E. S. Muxfeldt, C. R. L. Cardoso, V. B. Dias, A. C. M. Nascimento, and G. F. Salles, "Prognostic impact of the ambulatory arterial stiffness index in resistant hypertension," Journal of Hypertension, vol. 28, no. 7, pp. 1547-1553, 2010.

[53] G. F. Salles, C. R. L. Cardoso, R. Fiszman, and E. S. Muxfeldt, "Prognostic significance of baseline and serial changes in electrocardiographic strain pattern in resistant hypertension," Journal of Hypertension, vol. 28, pp. 1715-1723, 2010.

[54] G. F. Salles, C. R. L. Cardoso, and E. S. Muxfeldt, "Prognostic value of ventricular repolarization prolongation in resistant hypertension: a prospective cohort study," Journal of Hypertension, vol. 27, no. 5, pp. 1094-1101, 2009.

[55] M. M. F. Magnanini, A. D. R. Nogueira, M. S. Carvalho, and K. V. Bloch, "Ambulatory blood pressure monitoring and cardiovascular risk in resistant hypertensive women," Arquivos Brasileiros de Cardiologia, vol. 92, no. 6, pp. 448-489, 2009.

[56] A. Benetos, F. Thomas, K. Bean, S. Gautier, H. Smulyan, and L. Guize, "Prognostic value of systolic and diastolic blood pressure in treated hypertensive men," Archives of Internal Medicine, vol. 162, no. 5, pp. 577-581, 2002.

[57] H. M. Perry, J. P. Miller, J. R. Fornoff et al., "Early predictors of 15-year end-stage renal disease in hypertensive patients," Hypertension, vol. 25, no. 4 I, pp. 587-594, 1995.

[58] B. Dahlöf, P. S. Sever, N. R. Poulter et al., "Prevention of cardiovascular events with an antihypertensive regimen of amlodipine adding perindopril as required versus atenolol adding bendroflumethiazide as required, in the AngloScandinavian Cardiac Outcomes Trial-Blood Pressure Lowering Arm (ASCOT-BPLA): a multicentre randomised controlled trial," The Lancet, vol. 366, no. 9489, pp. 895-906, 2005.

[59] K. Jamerson, M. A. Weber, G. L. Bakris et al., "Benazepril plus amlodipine or hydrochlorothiazide for hypertension in highrisk patients," The New England Journal of Medicine, vol. 359, no. 23, pp. 2417-2428, 2008.

[60] C. D. Furberg, J. T. Wright Jr., B. R. Davis et al., "Major outcomes in high-risk hypertensive patients randomized to angiotensin-converting enzyme inhibitor or calcium channel blocker vs diuretic: the antihypertensive and lipid-lowering treatment to prevent heart attack trial (ALLHAT)," Journal of 
the American Medical Association, vol. 288, no. 23, pp. 29812997, 2002.

[61] M. A. Weber, H. Black, G. Bakris et al., "A selective endothelinreceptor antagonist to reduce blood pressure in patients with treatment-resistant hypertension: a randomised, doubleblind, placebo-controlled trial," The Lancet, vol. 374, no. 9699, pp. 1423-1431, 2009.

[62] G. L. Bakris, L. H. Lindholm, H. R. Black et al., "Divergent results using clinic and ambulatory blood pressures: report of a darusentan-resistant hypertension trial," Hypertension, vol. 56, no. 5, pp. 824-830, 2010.

[63] I. J. M. Scheffers, A. A. Kroon, J. Schmidli et al., "Novel baroreflex activation therapy in resistant hypertension: results of a European multi-center feasibility study," Journal of the American College of Cardiology, vol. 56, no. 15, pp. 1254-1258, 2010.

[64] H. Krum, M. Schlaich, R. Whitbourn et al., "Catheter-based renal sympathetic denervation for resistant hypertension: a multicentre safety and proof-of-principle cohort study," The Lancet, vol. 373, no. 9671, pp. 1275-1281, 2009. 


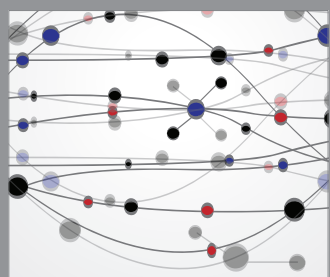

The Scientific World Journal
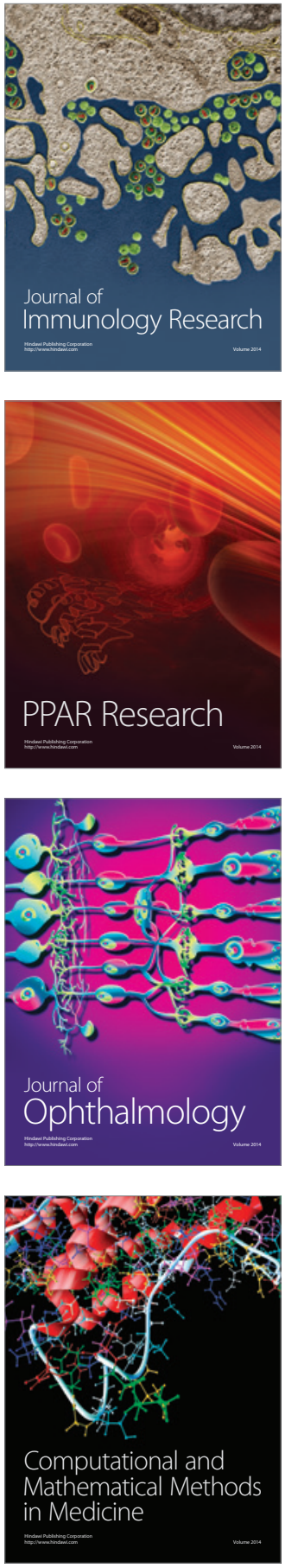

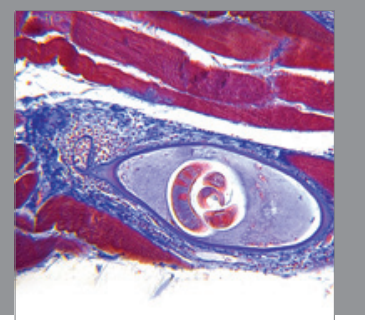

Gastroenterology

Research and Practice
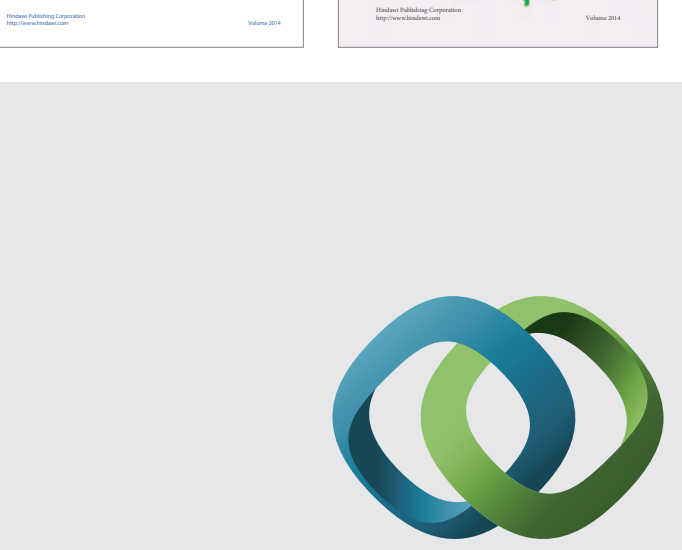

\section{Hindawi}

Submit your manuscripts at

http://www.hindawi.com
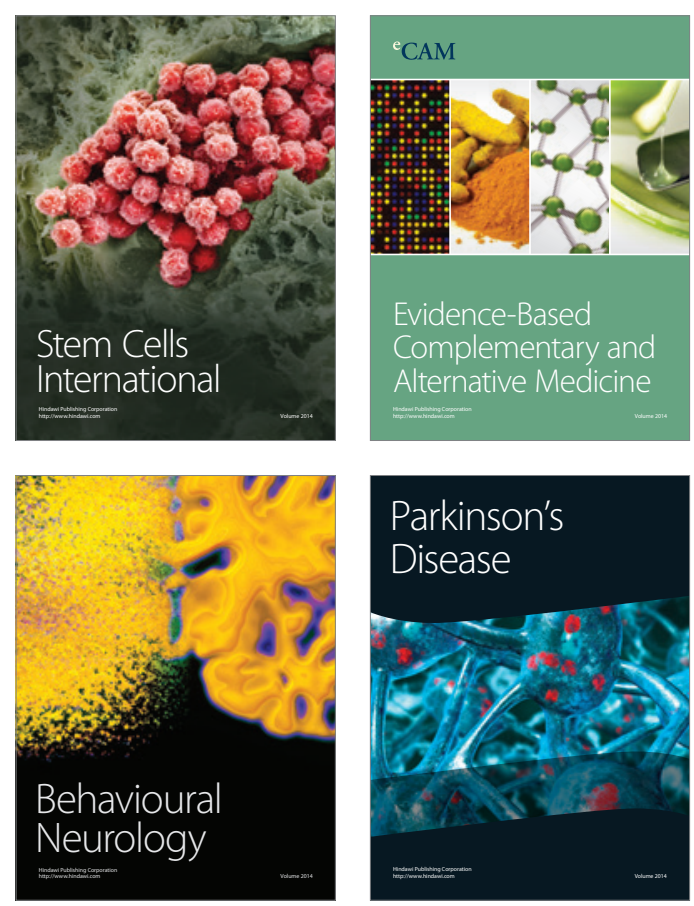

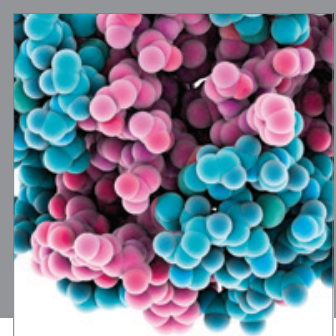

Journal of
Diabetes Research

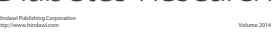

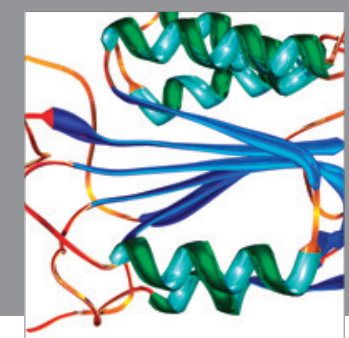

Disease Markers
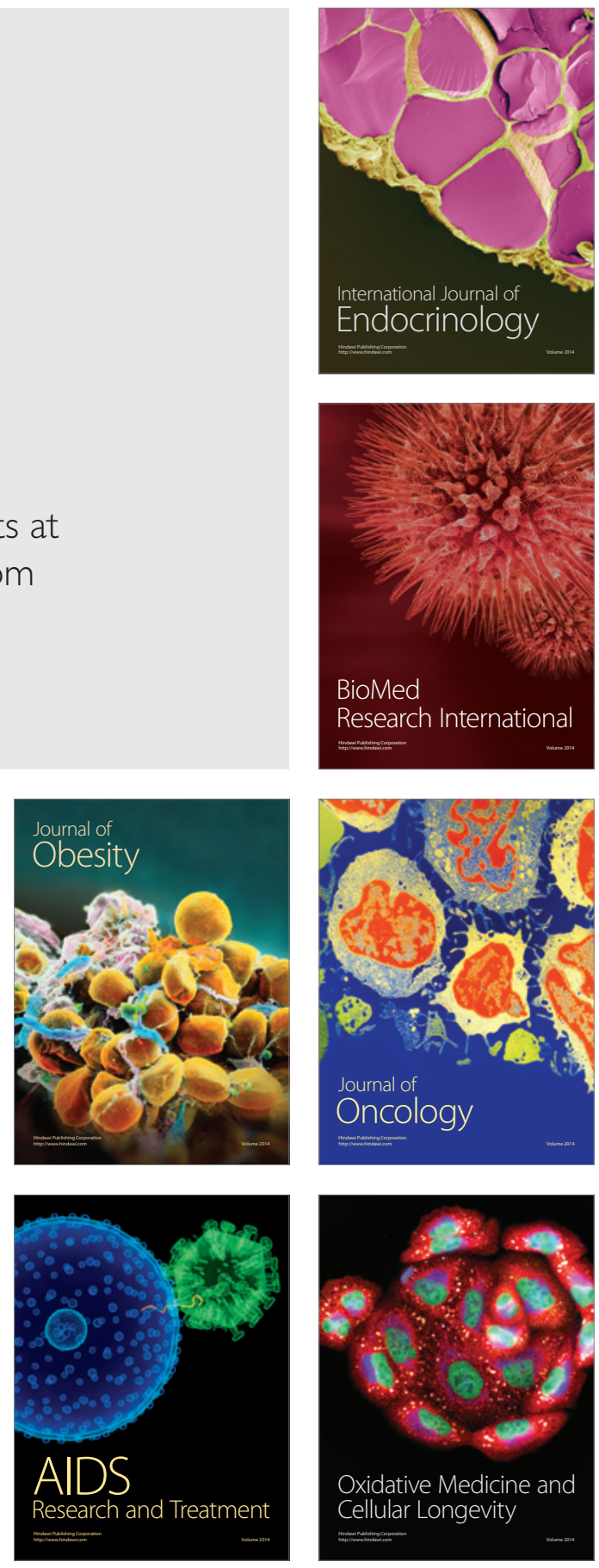